\section{RNA's catalytic role}

\section{London}

THIs year's Nobel prize for chemistry has been awarded jointly to Sidney Altman of Yale University and Thomas Cech of the University of Colorado, Boulder, for their independent discoveries that RNA can have catalytic activity. These discoveries may have profound implications for our understanding of the origin of life, and may also lead to important practical developments.

Biological catalysis had previously been considered the exclusive domain of protein enzymes. RNA is usually thought of as a passive informational molecule, though specific RNA molecules have long been known to have non-informational roles in protein synthesis.

One of the central problems in understanding how life could have originated is activity. They thought the RNA may be involved in recognizing the RNA substrates of ribonuclease $\mathrm{P}$, but at first did not consider a catalytic role for the RNA component to be a serious possibility.

Meanwhile, Thomas Cech and his colleagues were investigating the process by which the 'intervening sequence' of the precursor of a ribosomal RNA of the protozoan Tetrahymena thermophila is excised and the flanking 'exons' joined to make the mature ribosomal RNA product.

In 1982 Cech's group obtained conclusive evidence that this excision and ligation process can occur spontaneously in the absence of any protein catalyst (Cell 31, 147-157; 1982). Although not true catalysis, Cech's discovery provided the first firm evidence that RNA may be capable of specific catalysis. Altman and

\section{IMAGE UNAVAILABLE FOR COPYRIGHT REASONS}

Celebrations Colorado style, Thomas Cech (left) and at Yale, Sidney Altman. (AP.)

posed by the interdependence of modern systems of informational molecules, such as DNA, and functional molecules such as proteins. Consideration of this problem led to speculation by the pioneers of molecular biology in the 1960 s, most notably by Francis Crick, that catalytic RNA combining informational and functional properties might provide a solution to the seemingly intractable "chicken-andegg' problem. But such ideas were pure speculation until Altman and Cech, both working on RNA processing systems, demonstrated that RNA can indeed have catalytic properties similar to those of protein enzymes.

Altman's work concerned the bacterial enzyme ribonuclease $P$, which catalyses a specific cleavage reaction in the synthesis of mature tRNA molecules from larger precursors. In the 1970 s Altman and colleagues had shown that ribonuclease $P$ has RNA and protein components, both of which are essential for its enzymatic
NOBEL DISPUTE

\section{French researcher asks for share}

Paris

LAST week's award of the Nobel prize in medicine to the Americans, J. Michael Bishop and Harold E. Varmus (see Nature 341,$475 ; 12$ October 1989 ), has been greeted with sourness in France.

Dominique Stehelin, who is now director of research at a National Scientific Research Centre (CNRS) laboratory at the Pasteur Institute in Lille, said last week that it was he who carried out the work that led to the demonstration of the cellular character of oncogenes. A postdoctoral fellow in Bishop and Varmus' laboratory in the early 1970 s, Stehelin was the first author of papers in Nature and the Journal of Molecular Biology announcing the discovery.

"I did all the work from A to Z", Stehelin told Agence France Presse on hearing that he would not share the Nobel with Bishop and Varmus.

Stehelin has since softened his position, saying that he does not contest the decision of the Nobel jury, but still wonders why they could not have added a third name to the prize. Meanwhile, the director-general of CNRS, Francois Kourilsky, issued a statement congratulating Bishop and Varmus on the award but adding that "on this occasion, CNRS wishes to salute the role played by one of its researchers, Dominique Stehelin, in this discovery".

This role was sufficiently significant, says the statement, to earn Stehelin the Rosen and Griffuel prizes and the CNRS silver medal.

Peter Coles

- Bishop and Varmus have not commented directly on Stehelin's complaint, but numerous colleagues have come to their defence. According to the Washington Post, Peter Vogt, the fourth author on the Nature paper, said that Stehelin's unhappiness was "understandable but regrettable". A statement issued by the University of California at San Francisco made it clear that Stehelin's work was done "under supervision".

nucleotides aligned on an external template (Nature 339, 519-522; 1989).

The practical consequences inherent in these discoveries stem from the prospect of being able to manipulate specific RNA molecules in cells with RNA catalysts. An important step towards this goal was achieved last year by the construction of RNA catalysts derived from 'self-cleaving' plant-virus satellite RNA capable of cleaving other RNA molecules at highly specific, predetermined positions. This opens the possibility of using RNA catalysts to block the expression of specific genes in cells and organisms, may also lead to a new way of preventing virus infections, and has already led to a patents dispute involving Cech (Nature 341, 473; 1989).

Geoffrey North 